\section{Container Dimension Affects Rooting Medium Temperature Patterns}

\author{
Chris A. Martin ${ }^{1}$ \\ Department of Botany, Arizona State University, Tempe, AZ 85287-1601
}

Dewayne L. Ingram ${ }^{2}$

Department of Horticulture and Landscape Architecture, University of Kentucky, Lexington, KY 140546-0091

Additional index words. computer modeling, heat stress, nursery production

\begin{abstract}
Computer modeling was used to study the effect of container volume and shape on summer temperature patterns for black polyethylene nursery containers filled with a 4 pine bark : 1 sand (v/v) rooting medium and located in Phoenix, Ariz. (lat. 33.5 ${ }^{\circ}$, long. $112^{\circ} \mathrm{W}$ ) or Lexington, Ky. (lat. $38.0^{\circ} \mathrm{N}$, long. $84.4^{\circ} \mathrm{W}$ ). For both locations, medium temperatures were highest at the east and west container walls, halfway down the container profile, regardless of container height $(20$ to $50 \mathrm{~cm})$ or volume $(10$ to 70 liters). The daily maximum medium temperature $\left(T_{\max }\right)$ at the center was lower and occurred later in the day as container volume was increased because of an increased distance to the container wall. For both locations, predicted temperature patterns in rooting medium adjacent to the container wall decreased as the wall tilt angle (TA) increased. Predicted temperature patterns at the center of the container profile were lowered in response to the interaction of increased container height and wall TA. As container height decreased, the container wall TA necessary to lower center $T_{\max }$ to $\leq 40 \mathrm{C}$ increased; however, the required increase in TA was greater for Phoenix than for Lexington, principally because of higher ambient air temperatures.
\end{abstract}

Growth of containerized plants is slowed by supraoptimal root-zone temperatures (Graves, 1991; Martin and Ingram, 1991a; Martin et al., 1989). Daily maximum temperatures $>50 \mathrm{C}$ have been recorded in rooting media adjacent to east and west container walls, and temperatures $>40 \mathrm{C}$ have been recorded for 6 to $10 \mathrm{~h}$ daily during the summer at the center of the medium profile (Martin and Ingram, 1988). The root and shoot growth responses of several plant species to supraoptimal root-zone temperatures suggest that nursery operators should maintain rootzone temperatures $<40 \mathrm{C}$ to attenuate root injury and preserve satisfactory plant growth (Ingram et al., 1989; Martin et al., 1989, 1991; Wong et al., 1971; Yeager et al., 1991).

Solar radiation striking container walls is the primary source of thermal energy that causes supraoptimal rooting medium temperatures (Martin and Ingram, 1992). Thus, the most efficient cultural management strategies toameliorate high root-zone temperatures include those that decrease the influx of radiant energy into the rooting medium, such as different container color, close container spacing, and more overhead shade (Ingram, 1981; Keever and Cobb, 1984; Laiche, 1985; Martin and Ingram, 1991b). Different container dimensions also might alleviate supraoptimal

\footnotetext{
Received for publication 28 Feb. 1992. Accepted for publication 24 Aug. 1992. The cost of publishing this paper was defrayed in part by the payment of page charges. Under postal regulations, this paper therefore must be hereby marked advertisement solely to indicate this fact.

${ }^{1}$ Assistant Professor.

${ }^{2}$ Professor.
}

rooting medium temperatures. For example, the typical polyethylene nursery container has walls that are tilted outward about $\leq 5^{\circ}$ from perpendicular to a horizontal surface. Containers with walls tilted outward at greater angles might lead to lower rooting medium temperatures because of attenuated radiation fluxes onto the container wall.

This paper reports research that used computer modeling to investigate the effect of increased container volume or different container shape on rooting medium temperature patterns at two geographiclocations. Computer modeling was an effective research tool for this study because of the ease of manipulating container dimensions and the difficulty of obtaining unusually shaped containers from plastics manufacturers.

A computer model was constructed previously to simulate temperature patterns in black polyethylene, cylindrical containers filled with container media (Martin and Ingram, 1992). Sensitivity analysis and validation studies with real-time data have established confidence intervals of $>95 \%$ precision for the model's capability to predict container medium temperature patterns as a function of geographical location and environmental inputs (Martin and Ingram, 1992). This earlier model was modified to consider changes in the contact angle of direct solar radiation fluxes on container walls and container volume. Direct solar radiation $\left(\mathrm{W} \cdot \mathrm{m}^{-2}\right)$ on the container wall (IDNP) was calculated as THETA $=[0.9953 \times \cos ($ BETA $)$ $\times \cos (\mathrm{SSA})]-[0.096 \times \sin (\mathrm{BETA})]$; IDNP $=$ IDN $\times$ THETA, where THETA $=$ angle of irradiance relative to container wall tilt angle (TA); BETA = solar altitude angle (radian); SSA = surface-solar azimuth (radian); and
IDN $=$ direct solar irradiance $\left(\mathrm{W} \cdot \mathrm{m}^{-2}\right)$ on a horizontal surface. The thermal properties for polyethylene containers and rooting medium were not modified from earlier modeling work (Martin and Ingram, 1992); thus, our confidence in the model's predictive precision remains unchanged. For the present studies, simulation data were generated for two climatically dissimilar locations in the United States-Phoenix, Ariz., and Lexington, Ky.on Julian day 201 (20 July). In one study, diurnal temperature patterns were predicted for a 4 pine bark : 1 sand $(\mathrm{v} / \mathrm{v})$ rooting medium in 10- to 70-liter containers. Container volume was manipulated by adjusting container height, top diameter, and bottom diameter equally at a 1: 1: 1 ratio. In another study, diurnal temperature patterns were predicted for a 4 pine bark : 1 sand $(\mathrm{v} / \mathrm{v})$ rooting medium in containers that were 20 to $50 \mathrm{~cm}$ high with 0 to $45^{\circ}$ wall TAs. For each container height, the container TA was tilted outward from perpendicular to a horizontal surface (TA $=0)$ to $45^{\circ}$ by maintaining container height and bottom diameter at a constant ratio while increasing top diameter. For all computer simulations, the weather was assumed to be clear at both locations. Average maximum and minimum air temperatures (39.8 and $24.9 \mathrm{C}$ for Phoenix and 30.2 and $18.8 \mathrm{C}$ for Lexington, respectively) were computer-generated using the WGEN model for weather variables (Richardson and Wright, 1984). Diurnal air temperature patterns were calculated based on a sinusoidal relationship (Martin and Ingram, 1992). For all simulation runs, relative humidity was held constant at $15 \%$ for Phoenix and $65 \%$ for Lexington. Wind speed was a constant 2 $\mathrm{m} \cdot \mathrm{s}^{-1}$ at both locations. The rooting medium volumetric water content and temperatures were initialized at $40 \%$ and $26 \mathrm{C}$, respectively. Nursery containers were assumed to be on a black ground cover and exposed fully to solar radiation. Model data were analyzed by SAS PROC GLM linear regression procedures (SAS Institute, 1988).

For Phoenix and Lexington, rooting medium temperature patterns at all points within the container profile displayed sinusoidal wave patterns that were a function of 1 ) container and rooting medium thermal properties, 2) location of the point within the rooting medium profile, and 3) solar radiation incident angle and duration. At both geographical locations, the highest predicted rooting medium tem-

Table 1.Predicted maximum temperatures $\left(\mathrm{T}_{\max } ;{ }^{\circ} \mathrm{C}\right)$, $2.5 \mathrm{~cm}$ inside the east and west walls of a black polyethylene nursery container and halfway down the container profile, for black polyethylene containers filled with 4 pine bark : 1 sand $(\mathrm{v} / \mathrm{v})$ medium and located in Phoenix, Ariz. (lat. $33.5^{\circ} \mathrm{N}$, long. $112^{\circ} \mathrm{W}$ ) or Lexington, Ky. (lat. $38.0^{\circ} \mathrm{N}$, long. $\left.84.4^{\circ} \mathrm{W}\right)$ on Julian day $201(20$ July).

\begin{tabular}{lcc}
\hline \hline \multirow{2}{*}{$\begin{array}{l}\text { Geographic } \\
\text { location }\end{array}$} & \multicolumn{2}{c}{ Container media coordinate } \\
\cline { 2 - 3 } & East & West \\
\hline Phoenix & $46.0 \pm 1.1^{\mathrm{z}}$ & $56.0 \pm 1.0$ \\
Lexington & $40.7 \pm 0.9$ & $48.6 \pm 0.7$ \\
\hline
\end{tabular}

${ }^{x}$ Predicted temperatures are means for containers with volumes ranging from 10 to 70 liters, $n=27$. 

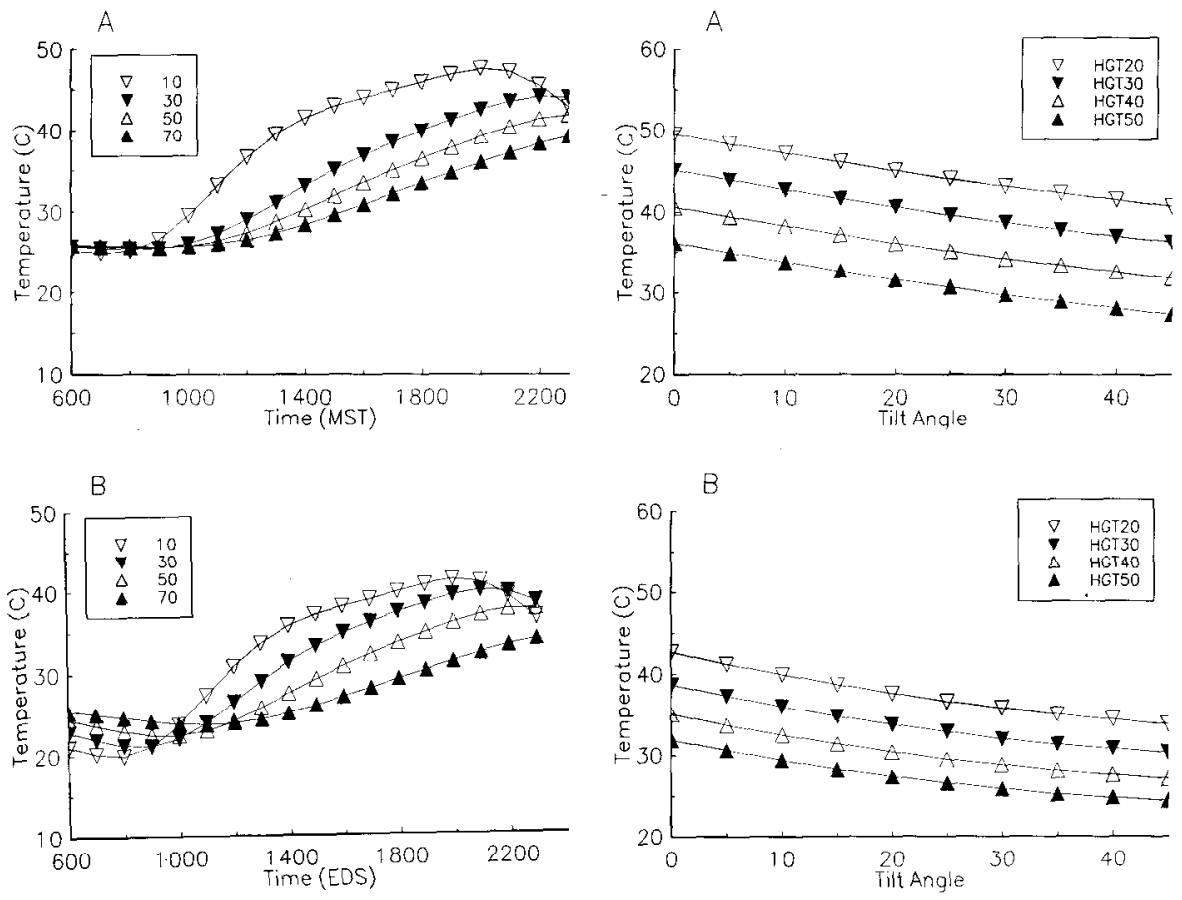

Fig. 1. The effect of increased container volume (range 10 to 70 liters) on predicted maximum daily temperature at the center of a rooting medium profile for black polyethylene containers filled with 4 pine bark : 1 sand $(v / v)$ medium and located in (A) Phoenix, Ariz. (lat. $33.5^{\circ} \mathrm{N}$, long. $112^{\circ} \mathrm{W}$ ) or (B) Lexington, Ky. (lat. $38.0^{\circ} \mathrm{N}$, long. $84.4^{\circ} \mathrm{W}$ ) on Julian day 201 ( $20 \mathrm{July}$ ).

peratures were immediately inside the east and west container walls, halfway down the container profile, regardless of container height (Table 1). In contrast, the predicted $\mathrm{T}_{\max }$ at the center was lower and occurred later in the day as container volume was increased (Fig. $1 \mathrm{~A}$ and $\mathrm{B}$ ). For Phoenix and Lexington, $\mathrm{T}_{\max }$ at the center was lowered by 8.8 and $6.4 \mathrm{C}$, respectively, as volume was increased from 10 to 70 liters. When container walls were exposed to solar radiation, the predicted temperature gradients from the wall to the medium center were negatively curvilinear. The rate of thermal energy movement into a container medium is defined by the rooting medium's thermal properties (Martin and Ingram, 1991a). Increased container width would modify diurnal temperature fluctuations at the center because the distance to the container wall is greater. Thus, for both locations, small plants transplanted into large or wide containers would be shielded more from the highest medium temperatures than plants in small or narrow containers because of the greater distance to the container wall.

Predicted diurnal temperature patterns in container medium adjacent to the container wall decreased as TA was increased. For

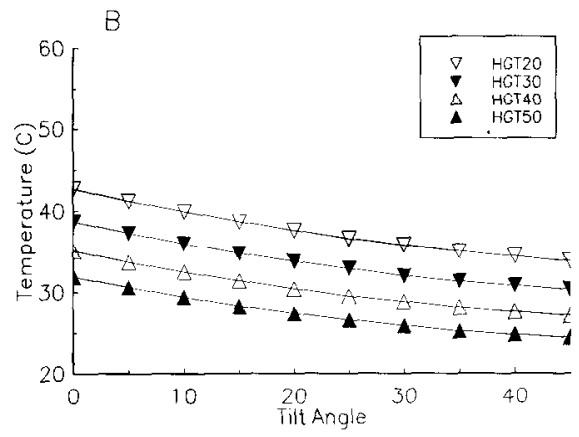

Fig. 2. The effect of container height ( 20 to $50 \mathrm{~cm}$ ) and wall tilt angle $\left(0\right.$ to $\left.45^{\circ}\right)$ on predicted maximum daily temperature at the center of a rooting medium profile for black polyethylene containers filled with 4 pine bark : 1 sand $(v / v)$ medium and located in (A) Phoenix, Ariz. (lat. $33.5^{\circ} \mathrm{N}$, long. $112^{\circ} \mathrm{W}$ ) or (B) Lexington, Ky. (lat. $38.0^{\circ} \mathrm{N}$, long. $\left.84.4^{\circ} \mathrm{W}\right)$ on Julian day $201(20$ July). HGT20, HGT30, HGT40, and HGTS0 = height at $20,30,40$, and $50 \mathrm{~cm}$, respectively.

Phoenix, $\mathrm{T}_{\max }$ at east and west exposures decreased linearly as TA was increased from 0 to $45^{\circ}$ (east, $\mathrm{T}_{\max }=54.9-0.37 \mathrm{TA}, r^{2}=0.97$; west, $\left.\mathrm{T}_{\max }=64.1-0.25 \mathrm{TA}, r^{2}=0.99\right)$. If TA was $40.3^{\circ}$, then east $\mathrm{T}_{\max }=40 \mathrm{C}$; however, when TA was $45^{\circ}$, west $T_{\text {max }}$ was still $>40 \mathrm{C}$. For Lexington, east and west $\mathrm{T}_{\max }$ decreased linearly as TA was increased from 0 to $45^{\circ}$ (east, $\mathrm{T}_{\max }=49.5-0.31 \mathrm{TA}, r^{2}=0.99$; west, $\mathrm{T}_{\max }=$ 57.1-0.24TA, $\left.r^{2}=0.99\right)$. WhenTAwas $30.6^{\circ}$, east $\mathrm{T}_{\max }=40 \mathrm{C}$; however, when TA was $45^{\circ}$, west $T_{\max }$ was still $>40 \mathrm{C}$.

Predicted diurnal temperature patterns at the container profile center decreased in response to the increased container height and wall TA interaction (Fig. 2 A and B). For both locations, as container height was decreased, the TA necessary to lower daily $\mathrm{T}_{\max }$ at the center to $\leq 40 \mathrm{C}$ was increased, however, the required TA increase was greater for Phoenix than for Lexington because of higher ambient air temperatures. For Phoenix, container height had to be $\geq 23.5 \mathrm{~cm}$ before $\mathrm{TA} \leq 45^{\circ}$ resulted in a maximum center temperature $\leq 40 \mathrm{C}$. In contrast, when container height was increased to $35 \mathrm{~cm}$, a $13.7^{\circ}$ TA could maintain the maximum center temperature below 40C. For Lexington, when container height was $20 \mathrm{~cm}$ and
$\mathrm{TA}=0, \mathrm{~T}_{\max }$ at the center was $43.3 \mathrm{C}$. If TA was increased by only $6.5^{\circ}, \mathrm{T}_{\text {max }}$ at the center was $39.8 \mathrm{C}$, and if TA was increased to $34^{\circ}$, the daily $\mathrm{T}_{\max }$ was lowered to $35.5 \mathrm{C}$. These data suggest that large containers with walls tilted outward may be practical for container nursery production in hot climates to lower rootzone temperatures because of the high ambient air temperatures during the summer. In moderate climates, small containers tilted outward may be used alone, or in addition to the cultural management practices mentioned previously. Large containers with tilted walls are unnecessary in moderate climates.

\section{Literature Cited}

Graves, W.R. 1991. Growth and iron content of three legume tree species at high root-zone temperature. J. Arboriculture 17:313-317.

Ingram, D.L. 1981. Characterization of temperature fluctuations and woody plant growth in white poly bags and conventional black containers. HortScience 16:762-763.

Ingram, D.L., C.A. Martin, and J.M. Ruter. 1989. Heat-stress of container-grown plants. Intl. Plant Prop. Soc. Proc. 39:348-353.

Keever, G.S. and G.S. Cobb. 1984. Container and production bed mulch effects on media temperatures and growth of 'Hershey's' red azalea. HortScience 19:439-441.
Laiche, A.J. 1985. Effect of time of spacing on the growth of container-grown llex cornuta 'Dwarf Burford', Lindl. and Paxt., and Pittosporum tobira. J. Environ. Hort. 3:22-24.

Martin, C.A. and D.L. Ingram. 1988. Temperature dynamics in black poly containers. Southern Nurseryman Res. Conf. 33:71-74.

Martin, C.A. and D.L. Ingram. 1991a. Root growth of southern magnolia following exposure to high root-zone temperatures. HortScience 26:370-371.

Martin, C.A. and D.L. Ingram. 1991b. Evaluation of thermal properties in container media and effect of irrigation on temperature dynamics in container media. J. Environ. Hort. 9(1):24-28.

Martin, C.A. and D.L. Ingram. 1992. Simulation modeling of temperatures in root container media. J. Amer. Soc. Hort. Sci. 117:571-577.

Martin, C.A., D.L. Ingram, and T.A. Nell. 1989. Supraoptimal root-zone temperature alters growth and photosynthesis of holly and elm. J. Arboriculture 15:272-276.

Martin, C.A., D.L. Ingram, and T.A. Nell. 1991. Growth and photosynthesis of Magnolia grandiflora 'St. Mary' in response to constant and increased container volume. J. Amer. Soc. Hort. Sci. 116:439-445.

Richardson, C.W. and D.A. Wright. 1984. WGEN: A model for generating daily weather variables. U.S. Dept. Agr., Agr. Res. Serv., ARS-8.

SAS Institute. 1988. SAS user's guide: Statistics. version 6.03 ed. SAS Institute, Cary, N.C.

Wong, T.L., R.W. Harris, and R.E. Fissell. 1971. Influence of high soil temperatures on five woody-plant species. J. Amer. Soc. Hort. Sci. 96:80-82.

Yeager, T.H., R.H. Harrison, and D.L. Ingram. 1991. 'Rotundifolia' holly growth and nitrogen accumulation influenced by supraoptimal rootzone temperatures. HortScience 26:1387-1388. 